\title{
PRÁTICAS DE LEITURA E CONDIÇÕES DE LETRAMENTO: IMPLICAÇÕES PARA A FORMAÇÃO DO PROFESSOR-LEITOR
}

\author{
Márcia Regina dos Reis ${ }^{1}$ \\ Rita Signor ${ }^{2}$
}

\section{Resumo}

O objetivo deste estudo é analisar as condições de letramento de 100 professores de $1^{\mathrm{a}}$. e $2^{\mathrm{a}}$. séries do ensino fundamental, considerando as práticas de leitura realizadas no contexto profissional e doméstico, a influência recebida durante a formação leitora e as possíveis dificuldades de leitura apresentadas pelos docentes. A pesquisa de campo ocorreu em escolas de cinco municípios do estado do Paraná. Para levantamento dos dados foi aplicado um questionário composto por 26 perguntas discursivas. Os dados foram analisados quantitativamente e qualitativamente à luz dos estudos do letramento. Constatamos, por meio de nossos resultados, que uma parcela significativa dos professores manifestou uma restrita relação com a prática da leitura. Ainda, $23 \%$ deles assumiram que têm dificuldades em interpretar textos. Concluímos que a escolarização básica e graduação centrada na transmissão de conteúdos podem ter sido decisivas para a formação de alguns docentes sem condições suficientes para o exercício da carreira pedagógica. O estudo aponta para a necessidade de dar voz ao professor nos cursos de formação e formação continuada para, por meio do seu discurso, traçar estratégias para poder atingi-lo realmente, o que inclui dar novos sentidos à sua relação com a leitura.

Palavras-chave: Práticas de leitura. Condições de letramento. Formação do professor. Formação do leitor.

\begin{abstract}
The main objective of this study is to analyze literacy conditions of 100 teachers that work with $1^{\mathrm{a}}$. and $2^{\mathrm{a}}$."série" of Brazillian basic level. We are going to consider their reading practice in professional and home contexts, the influence over them during their reading training and possible reading problems presented by these teachers. Our empirical research was developed in schools of five cities from Paraná state. In order to collect data, we made a questionnaire constituted by 26 essay questions. The data were analyzed quantitatively e qualitatively based on literacy studies. Thus we found that most of the teachers has a restricted relation with reading. Besides, $23 \%$ of the teachers assumed that have problems with interpreting texts. We concluded that basic schooling and graduation when centered on transmission of contents may be decisive to train teachers without enough conditions to follow a pedagogical career. This study points to the fact that is necessary to let the teachers say what they think on training courses. Thus, by means of their discourse, it will be possible to draw strategies to reach those teachers and give a new meaning to their relation with reading.
\end{abstract}

Keywords: Reading practices. Literacy conditions. Training of teachers. Training of readers.

\section{Introdução}

O interesse em pesquisar as condições de letramento de professores surgiu a partir da

\footnotetext{
1 Mestrado em Distúrbios da Comunicação com enfoque em Linguagem, aprendizagem e formação de professores, pela Universidade Tuiuti do Paraná (2009).

${ }^{2}$ Doutoranda em Linguística pela Universidade Federal de Santa Catarina - UFSC. Fonoaudióloga do Hospital Infantil Joana de Gusmão. E-mail ritasignor@gmail.com
} 
nossa atuação em departamentos de educação e escolas. Nesses contextos, queixas de professores relativas às dificuldades de leitura e escrita de seus alunos são bastante frequentes. Não raro, esses profissionais encaminham um número significativo de crianças ao setor de fonoaudiologia por entenderem que elas apresentam escrita com muitos “erros” ortográficos, produção de texto com pouca “criatividade”, por não gostar de ler ou por terem dificuldade em interpretar o que leem.

Essas queixas nos levaram a pensar sobre como o professor age diante dos processos de aprendizagem da leitura e escrita de seus alunos, uma vez que ele é o principal agente mediador desse processo. Tal indagação motivou a realização deste estudo. Refletimos aqui sobre as práticas de leitura de professores e as consequências da qualidade do que leem para os processos de apropriação da leitura e escrita de seus alunos.

Evidenciamos, em nossa experiência profissional, especialmente no atendimento às crianças encaminhadas pelas instituições escolares, que as práticas de ensino da Língua Portuguesa realizadas em sala de aula, normalmente, não têm viabilizado o acesso dos educandos ao uso efetivo da linguagem escrita, uma vez que grupo significativo de professores utilizam propostas pedagógicas pautadas quase que exclusivamente em atividades mecânicas e descontextualizadas, distanciando os alunos de práticas sociais de leitura e escrita.

Confrontamos essas reflexões geradas por nossa experiência clínica e educacional com dados divulgados pela imprensa, como, por exemplo, reportagem recente do jornal Folha de S. Paulo apontando que 33\% da população de São Paulo é constituída por "analfabetos funcionais”; pessoas que não conseguem ler e compreender textos que são usados no cotidiano da cidade, a saber, outdoors, panfletos, cartazes, placas etc. Percebemos que a realidade verificada nas instituições em que trabalhamos é compatível com os dados apresentados pelo jornal, uma vez que presenciamos alunos com grandes dificuldades na compreensão leitora e na produção escrita até mesmo de textos com mínima complexidade enunciativo-discursiva.

Cabe destacar ainda que dados de indicadores de alfabetismo, como o INAF (Indicador Nacional de Alfabetismo Funcional), sinalizam para o fato de que apenas 25\% da população do Brasil pode ser considerada plenamente alfabetizada. Acrescenta-se a esse dado que desde 2001, quando o exame começou a ser realizado, até 2009, a população não tem avançado em relação ao nível 3 (alfabetismo pleno).

Dados como esses reforçaram o questionamento a respeito das práticas pedagógicas 
que os professores vêm proporcionando aos alunos no contexto escolar. E mais, suscitam a realização de pesquisas.

O objetivo deste trabalho é analisar as condições de letramento de um grupo de professores de educação básica, considerando, sobretudo, as práticas de leitura realizadas no contexto profissional e doméstico, a influência recebida durante a formação leitora, e as possíveis dificuldades de leitura apresentada pelos professores. A pesquisa que apresentamos neste artigo é parte de uma dissertação de Mestrado em Distúrbios da Comunicação Humana.

Para tanto, adotamos a concepção sócio-histórica de linguagem e enfatizamos o conceito de letramento. Tal conceito, segundo Soares (2003), é recém-chegado ao vocabulário da educação e da linguística, tendo maior penetração nessas áreas a partir de 1986.

O termo letramento está relacionado às práticas sociais de leitura e escrita. Nessa perspectiva, a apropriação da linguagem escrita passa a ser vista de maneira dinâmica, envolvida com processos vinculados a contextos significativos (SOUZA, 2008). A respeito desse conceito, Cook-Gumpers (1986, p. 16) faz a seguinte afirmação: “é consenso social, nos dias de hoje, que o letramento é tanto o objetivo quanto o produto da escolarização”. Nesse sentido, defendemos que cabe ao professor promover o letramento com o objetivo de conduzir os alunos à apropriação da modalidade escrita da linguagem, bem como ao uso efetivo dessa modalidade em contextos variados.

\section{Método}

A pesquisa de campo deste estudo foi feita com professores de $1^{\mathrm{a}}$ e $2^{\mathrm{a}}$ série do ensino fundamental de oito anos, da rede pública de educação. A pesquisa foi realizada em cinco municípios que pertencem a duas regiões do Paraná. Os municípios de Ivaiporã e Arapuã fazem parte do norte do Paraná, onde a economia familiar é provida da agricultura. Os municípios de Colombo, Piraquara e Campina Grande do Sul fazem parte da região metropolitana de Curitiba, cuja economia familiar é predominantemente industrial.

Optamos por pesquisar as condições de letramento de professores que atuam nas séries iniciais por serem consideradas, no sistema educacional, como aquelas em que se inicia o processo de formação do sujeito-leitor.

As escolas visitadas em cada município ficaram a critério das Secretarias de Educação de cada cidade, que, por meio de ofício, indicaram as que poderiam ser incluídas na 
pesquisa. Nas instituições onde a pesquisa foi realizada, os professores que participaram foram aqueles que apresentaram disponibilidade de tempo, de acordo com a sua hora atividade.

Para levantamento dos dados foi aplicado, junto a 100 professores, um questionário composto de 26 perguntas discursivas que foram respondidas por escrito. As respostas foram analisadas quantitativamente e qualitativamente à luz dos estudos do letramento. Convém explicitar que todos os questionários foram aplicados nas instituições escolares em que atuam os sujeitos da pesquisa. As questões a serem respondidas por eles referiam-se às suas práticas de leitura e escrita no contexto profissional e doméstico/lazer; versavam, ainda, sobre possíveis influências recebidas durante a formação leitora e algumas questões estavam relacionadas a possíveis dificuldades de leitura e escrita. Neste trabalho, por questões de espaço, apresentamos apenas dados relativos à leitura. O questionário foi aplicado no período de agosto a outubro de 2007 e na presença das pesquisadoras.

Ressaltamos que, antecedendo a aplicação do questionário, os professores receberam esclarecimentos a respeito dos objetivos da pesquisa e sobre o sigilo quanto à identidade dos participantes. Depois das devidas explicações, os sujeitos da pesquisa assinaram um documento de livre participação e Termo de Consentimento Livre e Esclarecido.

Posteriormente ao preenchimento dos 100 questionários, as respostas dadas às questões foram sistematizadas em categorias elencadas a partir das semelhanças encontradas nos relatos dos respondentes. As categorias selecionadas com base nos discursos escritos dos professores que participaram do estudo foram explicitadas nos gráficos e nas tabelas referentes a cada questão. Esclarecemos que, para a digitação, computação e conversão dos dados em tabelas e gráficos, utilizamos o programa computacional Sphinx. Vale referir que os relatos escritos dos professores são identificados pela letra P acompanhada dos números de 1 a 100 (P1 a P50 relatos dos professores que atuam no norte do Paraná; P51 a P100 - relatos de professores que trabalham na região metropolitana de Curitiba).

Enfatizamos que a sistematização dos dados coletados procurou, além de caracterizar a amostra, respeitar as temáticas que abordam as práticas de leitura e escrita nos contextos profissional, doméstico/lazer, seguindo o objetivo proposto neste trabalho.

Esta pesquisa ${ }^{1}$ foi aprovada pelo Comitê de Ética da Universidade Tuiuti do Paraná, sob o registro de número 1252.

\section{Resultados e discussão}


Trataremos nesta seção das influências, positivas e negativas, sofridas pelos professores no decorrer de sua história na sua relação com a leitura; das práticas de leitura vivenciadas nos contextos profissional e doméstico; e das dificuldades de interpretação de textos apresentadas pelos professores.

Em relação às influências recebidas para a prática da leitura, a maioria dos professores pesquisados, $82 \%$, referiram que pessoas os influenciaram de forma positiva. Somente 7\% dos professores afirmaram que alguém os influenciou negativamente. Já 5\% disseram não ter sido influenciados por alguém nesse aspecto. As pessoas apontadas como influências positivas podem ser encontradas na tabela 1.

TABELA 1-INFLUÊNCIAS POSITIVAS PARA A PRÁTICA DA LEITURA

\begin{tabular}{l|c|c}
\hline \multicolumn{1}{c|}{ INFLUÊNCIAS POSITIVAS } & NÚMERO DE CITAÇÕES & FREQUÊNCIA \\
\hline Professores & 55 & $55 \%$ \\
Família & 35 & $35 \%$ \\
Amigos & 9 & $9 \%$ \\
Respostas Incompreensíveis & 10 & $10 \%$ \\
Sem Resposta & 18 & $18 \%$ \\
\hline
\end{tabular}

FONTE: Pesquisa de campo, 2007

Constatamos que $55 \%$ dos professores afirmaram que foram influenciados positivamente por seus professores, sendo que, desse percentual, $16 \%$ atribuíram essa influência especificamente aos professores do ensino fundamental. 35\% declararam a relevância de um membro da família, sendo a mãe a pessoa mais citada (20\%). Somente 9\% mencionaram a influência de amigos.

Destacamos nesse processo a escola como importante agência de letramento. Nossa pesquisa mostra o professor como o maior influenciador na relação do aluno com a leitura, confirmando o relevante papel que ele tem no processo de letramento dos estudantes. Porém, esperávamos índices mais elevados em relação ao papel do professor, uma vez que sua função primordial está em fomentar o gosto pela leitura no aluno. A fim de elucidar essa afirmação, a da relevante influência do professor, segue o relato de um dos sujeitos que caracteriza a participação positiva do professor na sua relação com a leitura.

Minha professora do primário, como prêmio para o melhor leitor, doava um livro de literatura, com o qual fui premiada e me esforçava para ler com ritmo e entonação. (P. 97). 
Em detrimento da influência recebida, o excerto acima impressiona pela expressão “melhor leitor” e ao que ela significa. Geraldi (1997), ao tratar do papel da mediação entre professores e alunos nas ações de ensino da leitura em salas de aula, diz que tal relação pode se construir em uma situação de interação de várias formas: o texto pode ser objeto de leitura oralizada, em que os alunos leem partes do texto e os que mais se aproximam do padrão de fluência são considerados bons leitores (o que ilustra o caso acima); a leitura do texto pode ser um pretexto para que se produza escrita; ou a leitura de um texto pode ser compreendida como uma fixação de sentidos, ou seja, o significado do texto é o significado que lhe é imposto pelo mediador. No contraponto a essa última concepção, em uma atitude revolucionária, o valor do texto, seu sentido, fica restrito à significação individualizada que recebe em uma situação de leitura (perde-se o diálogo com o autor). Concordamos com Geraldi que, contrário a essas posições, afirma que a leitura deve se constituir como uma atividade de produção de sentidos em que o mediador pode, juntamente com seus aprendizes, ir mapeando as pistas fornecidas pelo texto e, através da análise destas pistas, ir construindo a compreensão do material lido (SIGNOR, 2010).

No caso do sujeito em questão (P97), o sentido de 'melhor leitor' está, de fato, atrelado ao de leitor mais fluente, uma vez que durante a sua formação leitora, foi esta a influência que recebeu. Resta-nos questionar se esse sentido formado durante sua escolarização perpassa sua prática pedagógica atual. Acreditamos que as situações de ensino e aprendizagem da leitura e escrita, pautadas exclusivamente em aspectos formais da língua, refletem, atualmente, muito das interações passadas e vivenciadas pelo professor durante a sua escolarização básica. Temos, como resultado desse processo social e histórico, "sintomas” nas condições de alfabetismo de um povo.

Ressaltamos, ainda, a influência positiva da família na relação com a leitura. Para exemplificação dessa influência, apresentamos os seguintes relatos:

A minha relação com os livros começou na infância pela influência de familiares, que me presenteavam com obras literárias. (P. 88)

Minha mãe (professora e leitora assídua), rata de biblioteca. (P. 13)

Desde muito cedo aprendi o valor da leitura com minha mãe, que me ensinou a gostar dessa verdadeira arte, que é ler. (P. 5)

É possível acreditar que a influência da família pode ocorrer de várias formas. Em um contexto familiar propício ao desenvolvimento do letramento, é comum crianças conviverem com muitos livros, habituarem-se a ouvir histórias lidas por seus pais; conviverem com os 
pais lendo e escrevendo; frequentarem livrarias, bibliotecas, ganharem livros de presente. Em tais condições, o letramento é bastante favorecido. Para Lahire (2008), a familiaridade com a leitura desde cedo pode ser decisiva para o sucesso escolar e para a formação leitora da criança. Para o autor,

a leitura em voz alta de narrativas escritas, combinada com a discussão dessas narrativas com a criança, está em correlação extrema de 'sucesso' escolar com a leitura. Quando a criança conhece, ainda que oralmente, histórias escritas lidas por seus pais, ela capitaliza - na relação afetiva com seus pais - estruturas textuais que poderá reinvestir em suas leituras ou nos atos de produção escrita (2008, p. 20).

O autor diz ainda que o livro e os outros materiais escritos fazem parte das ferramentas do cotidiano pelos quais a criança recebe afeto dos pais, fazendo com que a criança associe afeto e leitura.

Assim, podemos supor que alguns professores, que têm uma boa relação com a leitura, construíram-na também durante sua infância e adolescência, em meio a influência de familiares; algo que pôde ser constatado por meio dos relatos acima.

Outro dado que vale ser enfatizado aqui é a influência de amigos no incentivo à leitura. Alguns professores referiram que amigos, sobretudo do ambiente profissional (colegas de trabalho), contribuíram na relação favorável estabelecida com a leitura. Partindo desse resultado, e considerando que relações de amizade se estabelecem na escola, o professor poderia organizar atividades nas quais os alunos mais afetos à leitura pudessem compartilhar suas experiências com a leitura, auxiliando os colegas que não gostam de ler a ressignificar as suas próprias vivências com o material escrito. Aqui poderia ser explorada a ideia de que atividades grupais de leitura e escrita poderiam ser propostas com maior frequência, permitindo o compartilhar de histórias, de conhecimentos e de relações distintas estabelecidas com a leitura e escrita, bem como dos textos lidos e escritos.

Ainda, quanto às influências de leitura recebidas, dos pesquisados $10 \%$ deram respostas imprecisas, o que dificulta a caracterização específica, por exemplo:

Muitas pessoas. (P. 52)

O fato de ter voltado a estudar. (P. 63)

Salientamos que $18 \%$ dos pesquisados não responderam a essa questão, deixando-a em branco. Sendo índices oriundos de professores, o significativo percentual leva-nos a 
pensar sobre a trajetória escolar e acadêmica deles, haja vista que nenhum professor foi lembrado e citado por esses sujeitos.

No que diz respeito à leitura no contexto profissional, $100 \%$ dos professores pesquisados afirmaram ler nesse contexto; sendo que 43\% disseram realizar essa prática diariamente, $36 \%$, semanalmente e $20 \%$, mensalmente. $1 \%$ não indicou a frequência.

Os pesquisados declararam ler, sobretudo, livros didáticos e textos da área da educação, além de textos informativos e livros diversos. A tabela 2, a seguir, especifica em porcentagem o que os professores costumam ler no contexto profissional.

\section{TABELA 2- HÁBITOS DE LEITURA NO CONTEXTO PROFISSIONAL}

\begin{tabular}{l|c|c}
\hline LEITURA NO CONTEXTO PROFISSIONAL & NÚMERO DE CITAÇÕES & FREQUÊNCI \\
\hline Textos e livros referentes à educação & 43 & $43 \%$ \\
Textos informativos & 29 & $29 \%$ \\
Textos didáticos/conteúdos & 27 & $27 \%$ \\
Livros diversos & 22 & $22 \%$ \\
Revistas & 21 & $21 \%$ \\
Jornais & 14 & $14 \%$ \\
Internet & 10 & $10 \%$ \\
Poesias & 6 & $6 \%$ \\
Avaliações/atividades/cadernos dos alunos & 5 & $5 \%$ \\
Artigos & 4 & $4 \%$ \\
Lendas & 1 & $1 \%$ \\
Contos & 1 & $1 \%$ \\
Músicas & 1 & $1 \%$ \\
Recados & 1 & $1 \%$ \\
Respostas Incompreensíveis & 10 & $10 \%$ \\
Sem Resposta & 1 & $1 \%$ \\
\hline FONTE: Pesquisa de campo, 2007 & &
\end{tabular}

Podemos verificar que $43 \%$ das leituras realizadas são referentes a textos e livros sobre educação, $29 \%$ a textos informativos, $27 \%$ a textos didáticos, $22 \%$ realizam leitura de livros diversos, $21 \%$ citaram a leitura de revistas, $14 \%$ citaram jornais e $10 \%$ mencionaram a internet.

Relativamente a esses dados, percebe-se que as escolhas dos materiais escritos atendem principalmente às necessidades de informações a respeito da área de atuação, como já mencionamos. Nesse contexto, como revelam os dados, os professores são leitores, e o que eles vêm lendo parece ser para obter informações referentes à sua prática em sala de aula. Vejamos o relato de um dos professores: 
O que nos chama atenção em relação aos hábitos de leitura é que houve pouca menção às leituras não didáticas, como as leituras de gêneros discursivos relevantes ao desenvolvimento da linguagem escrita dos alunos, a saber, romances, contos, poesias, propagandas, crônicas, peças de teatro, piadas, notícias, reportagens, etc. Considerando que o professor é um formador de leitores, questionamos se não deveria haver maior abrangência na qualidade de suas leituras (mesmo em sala de aula em conjunto com os alunos) para que ele leitor com amplas experiências de leitura - pudesse desenvolver melhores e mais favoráveis condições para a formação de leitores competentes.

Kramer (1996) assevera que o professor não pode incentivar o aluno a praticar algo que ele próprio não faz. Segundo a autora, "para o professor tornar seus alunos leitores/escritores vivos precisa ser ele mesmo leitor e escritor” (1996, p. 9-10).

Posição semelhante sobre o papel do professor em proporcionar estratégias que possibilitem o desenvolvimento do gosto e da prática da leitura e da escrita em seus alunos, encontramos em Micarello e Freitas (2002):

\footnotetext{
O papel do professor na formação do gosto pela leitura e escrita é fundamental. O primeiro requisito para que o contato do aluno com o texto seja agradável é que o professor seja um leitor. Que ele goste de ler/escrever e pratique a leitura e a escrita. A verdade é que se torna impossível para o professor levar o aluno a produzir um sentido para sua leitura e escrita se ele próprio, professor, não produz um sentido para sua prática pedagógica (p. 134 e 135).
}

Contudo, percebemos por meio de alguns relatos, que alguns professores têm consciência sobre o fato de que amplas e diversificadas experiências com a leitura, são fundantes para criar no aluno o desejo por ler. Observemos:

No contexto profissional gosto de ler poesias, porque a partir consigo criar atividades e contextos que são interessantes para meus alunos. (P. 30)

Tenho prazer em ler no contexto profissional, pois gosto de ler e adquiro informações de tudo, além de ser exemplo aos alunos, professor leitor, alunos leitores. (P. 84)

A partir dos excertos acima, podemos verificar que o professor-leitor pode contribuir diretamente na formação do gosto do aluno pela leitura, já que nos constituímos na e por meio de nossas relações sociais. Dessa forma, a leitura compartilhada de diversos gêneros (da esfera jornalística, da esfera da arte, da esfera acadêmica etc) entre alunos e professores, como 
refere o sujeito P30, poderia se constituir em um recurso produtivo para a promoção do letramento no espaço da escola.

Outra questão levantada por este estudo diz respeito às práticas cotidianas de leitura; ou seja, analisamos as respostas dadas pelos professores quanto ao uso da leitura no contexto doméstico/lazer. Dos pesquisados, 83\% afirmaram ler e 27\% não. Os professores que disseram não ler justificaram a resposta alegando outras preferências, falta de tempo ou de hábito.

Para caracterizar as posições dos $27 \%$ de professores, apresentamos relatos de cinco deles que justificaram, de maneiras distintas, a não leitura no contexto em análise.

O meu lazer é outro e não envolve leitura. (P. 82)

Prefiro fazer atividades mais familiares como dançar, conversar, viajar e praticar artesanato. (P. 60)

Os momentos de lazer são poucos e prefiro bater papo. (P. 51)

Não tenho esse hábito. (P. 17)

Talvez porque não fui acostumada. (P. 12)

Nos relatos mencionados, podemos constatar que a leitura não é, de fato, uma atividade prazerosa para os professores em questão; isto é, está associada exclusivamente ao contexto profissional - lê-se apenas para o trabalho e em razão dele.

Os professores que costumam ler cotidianamente têm como prática a leitura de revistas diversas (63\%), receitas culinárias (54\%), jornais (46\%), livros diversos (36\%), bula de remédio (20\%), romances (19\%), livros de autoajuda (16\%), manuais de instrução e gibis (12\%), literatura e internet/e-mail (11\%). A tabela a seguir evidencia esses dados. 
TABELA 3 - HÁBITOS DE LEITURA NO CONTEXTO DOMÉSTICO/LAZER

\begin{tabular}{|c|c|c|}
\hline $\begin{array}{c}\text { LEITURA NO CONTEXTO } \\
\text { DOMÉSTICO }\end{array}$ & NÚMERO DE CITAÇÕES & FREQUÊNCIA \\
\hline Revistas diversas & 63 & $63 \%$ \\
\hline Receitas culinárias & 54 & $54 \%$ \\
\hline Jornais & 46 & $46 \%$ \\
\hline Livros diversos & 36 & $36 \%$ \\
\hline Bulas de remédio & 20 & $20 \%$ \\
\hline Romances & 19 & $19 \%$ \\
\hline Livros de auto ajuda & 16 & $16 \%$ \\
\hline Manuais de instrução & 12 & $12 \%$ \\
\hline Gibis & 12 & $12 \%$ \\
\hline Literatura & 11 & $11 \%$ \\
\hline Internet/e-mail & 11 & $11 \%$ \\
\hline Bíblia & 9 & $9 \%$ \\
\hline Rótulos & 8 & $8 \%$ \\
\hline Embalagens & 8 & $8 \%$ \\
\hline Leitura para auxiliar tarefa dos filhos & 8 & $8 \%$ \\
\hline Poemas & 6 & $6 \%$ \\
\hline Fulgires/panfletos & 5 & $5 \%$ \\
\hline Bilhetes/recados & 4 & $4 \%$ \\
\hline Letras de música & 4 & $4 \%$ \\
\hline Coquetel & 3 & $3 \%$ \\
\hline Receitas médicas & 2 & $2 \%$ \\
\hline Boletos de contas & 2 & $2 \%$ \\
\hline Piadas & 2 & $2 \%$ \\
\hline Textos & 2 & $2 \%$ \\
\hline Contos & 2 & $2 \%$ \\
\hline Livros de ficção & 2 & $2 \%$ \\
\hline Lista de compras & 1 & $1 \%$ \\
\hline Lista telefônica & 1 & $1 \%$ \\
\hline Textos dos alunos & 1 & $1 \%$ \\
\hline Outdoors & 1 & $1 \%$ \\
\hline Manuais de jogo & 1 & $1 \%$ \\
\hline Legendas & 1 & $1 \%$ \\
\hline Charges & 1 & $1 \%$ \\
\hline Catálogos & 1 & $1 \%$ \\
\hline Respostas Incompreensíveis & 13 & $13 \%$ \\
\hline Sem Resposta & 37 & $37 \%$ \\
\hline
\end{tabular}

FONTE: Pesquisa de campo, 2007

A esse respeito, a das escolhas dos professores, vale destacar alguns relatos relacionados às leituras realizadas:

No contexto lazer leio revistas e jornais pois mantém informado das notícias, fatos e eventos. (P. 38)

Leio revistas porque traz informações variadas. (P. 37)

Gosto de ler revistas de fofocas e algumas notícias de jornais. (P. 20) 
Faço leitura de revistas e jornais pois fico sabendo das novidades, das atualidades. (P. 73)

Importante considerar, nesse quesito, o sentido da leitura para o professor. É relevante considerar esse sentido, uma vez que a prática pedagógica é, em grande medida, atravessada por ele. Assim, o professor que tem uma relação favorável com a leitura, que tem amplas experiências com gêneros discursivos diversos e gosta realmente de ler, certamente contribuirá positivamente para a relação de seus alunos com a leitura também. Pensamos que um professor-leitor age promovendo uma boa relação dos alunos com as práticas de leitura, na medida em que serve de exemplo aos alunos, ao mesmo tempo em que tende a inserir os estudantes em práticas sociais de leitura e escrita, aproximando-os da linguagem escrita em meio a contextos significativos de uso da língua. Contudo, ao analisarmos os enunciados acima, uma amostra qualitativa do grupo em análise, observamos que o sentido prevalente é o da leitura-informação: ler para se manter informado sobre os "acontecimentos" (remete ao gênero notícia) e sobre as “fofocas” (entretenimento - rotina das celebridades).

Concordamos com Kramer e Souza (1996) quando afirmam que para o professor mediar práticas letradas é necessário que ele resgate o significado da leitura e da escrita em sua vida e em sua profissão, e então, ele poderá contribuir na formação de alunos autores efetivos de suas produções. As autoras ressaltam “a urgência do professor em conquistar sua palavra, recuperar o significado de sua profissão, se apropriar da leitura e que (re)descubra a paixão pela escrita” (p.10). Desse modo, é importantíssimo que o sentido da leitura para o professor seja resgatado para que, por meio desse significado, sejam pensadas práticas de (res)significação desses sentidos atribuídos à prática da leitura. O professor interessado em apenas se manter informado, seja das atualidades ou sobre as “celebridades”, demonstra uma relação restrita com a leitura; relação esta que necessita ganhar novos sentidos para que se possa implementar uma prática pedagógica coerente com sua situação de principal agente de letramento. O mais complicado, sob nosso modo de ver, é que $37 \%$ dos que afirmaram ler no contexto doméstico não mencionaram qualquer tipo de leitura realizada, e outros 13\% apresentaram "respostas incompreensíveis", demonstrando que quase metade da amostra pesquisada parece ser constituída por professores que não formaram uma relação afetiva e produtiva com o hábito da leitura.

Guedes-Pinto (2006), a esse respeito, defende que para despertar o gosto, o desejo no outro é necessário que se tenha o sentido de positividade em relação a essa prática, ou seja, é preciso gostar de ler e escrever para ensinar a gostar dessas atividades. 
Cabe ressaltar, entretanto, que em detrimento de a grande maioria dos professores manifestar uma restrita relação com a prática da leitura, alguns professores demonstraram possuir uma relação mais ampla, algo que pode ser notado no excerto abaixo:

Realizo leitura de livros de literatura, poemas, revistas e jornais, porque fico sabendo de notícias e informações. Em relação a literatura faz nos sentir livres na imaginação e no tempo, os poemas falam de sentimentos e consigo pensar a respeito de mim e refletir referente a vida. (P. 7).

Por fim, analisamos se os professores possuem dificuldades de leitura sob a ótica deles mesmos.

Ao serem questionados acerca de possíveis dificuldades em ler, 74\% dos professores afirmaram que não as têm, enquanto 23\% assumiram que as têm. Para explicitar as posições dos que têm problemas de interpretação, seguem algumas respostas fornecidas pelos professores:

Embora já tenho bom conhecimento, algumas vezes encontro dificuldades para fazer leitura das entrelinhas. (P. 38)

Muitos autores são de leitura difícil, a gente tem que ler algumas vezes mais para entender. (P. 35)

A falta de tempo e a correria do dia-a-dia. (P. 80)

O sujeito P38 cursa faculdade de letras e declarou que, no contexto profissional e no doméstico/lazer, realiza leituras diversas, como a de revistas, jornais e, às vezes, literatura, porém em frequências variadas.

Na sua citação, referiu ter dificuldade em realizar leitura nas entrelinhas. O sujeito provavelmente está se referindo à dificuldade em realizar inferências. O problema que vemos é que não foram citadas leituras muito complexas por parte desse professor, como romances mais densos da literatura brasileira ou leituras mais complicadas como as relacionadas ao campo da filosofia. As leituras citadas são as menor complexidade enunciativa, o que demonstra que talvez possua uma dificuldade importante de interpretação de textos .

Como ainda é um estudante de Letras e demonstra interesse por leituras variadas, é possível que com a prática intensa da leitura venha a superar os problemas atuais; algo desejável se considerarmos que sua profissão exige um adequado nível de alfabetismo para dar conta das demandas pedagógicas para a formação do leitor.

Esse dado, o das possíveis dificuldades apresentadas pelo professor, interessa bastante 
principalmente em um país como o Brasil, em que as condições de letramento dos professores são restritas. Há de se pensar nessas condições e em formas de investimentos na formação do professor para que se possa ter essas condições ampliadas e adequadas à situação de ensino formal em escolas. Há de se considerar ainda, sob um ponto de vista sócio-histórico, que o professor é oriundo, em grande medida, dos segmentos sociais mais desprivilegiados socialmente; desse modo, o entorno familiar desfavorável ao desenvolvimento do letramento, associado a uma prática pedagógica historicamente centrada na transmissão de conteúdos, completamente esvaziados da realidade cotidiana, podem ser decisivos para a formação de docentes com condições insuficientes para o exercício da carreira pedagógica.

Além das questões familiares e escolares (de formação básica), a formação acadêmica pouco contribui para promover o letramento do futuro docente.

Justina (2004, p. 366), ao abordar a questão dos cursos de formação do professor de Língua Portuguesa, diz que

\begin{abstract}
O que ocorre, porém, é que os cursos de formação de professores de língua materna continuam os mesmos, com os mesmos paradigmas de formação. Alunos que entram na faculdade de letras, na maioria das vezes, não têm uma prática intensa de leitura e escrita, e na graduação também não é oferecida a eles a oportunidade de gerar conhecimento a partir da reflexão. A formação desses profissionais está mais centrada na prática do repetir, do acúmulo de saberes, para a finalidade da posterior transmissão. Este perfil de transmissor de saberes escolares é que impede o professor, quando em formação, de adquirir as competências necessárias para ser um bom leitor de textos de vários gêneros e, principalmente, dos documentos oficiais de ensino (P.366).
\end{abstract}

Na mesma direção, Souza (2008) analisa as condições precárias de trabalho no que se refere ao acesso às práticas de leitura e escrita desde o início da formação acadêmica. Essa precariedade de condições gera consequências negativas no que diz respeito à relação que esses profissionais têm com a linguagem escrita. Assim, não basta estar inserido num programa de formação, pois isso, por si só, não assegura ao professor práticas de leitura e escrita efetivas. Nesse sentido, a interferência de políticas públicas com o propósito de modificar o perfil educacional de nosso país, com uma reformulação nos programas de formação se faz necessário, buscando aprimorar a formação do professor.

O sujeito P35, por sua vez, é graduado no curso normal superior e especialista em educação especial. No contexto profissional, a frequência de leitura é mensal; no contexto doméstico/lazer, é semanal. Os tipos de materiais que o professor costuma ler parecem não lhe proporcionar condições suficientes para realizar leitura em que há uma maior exigência em relação às condições de letramento do leitor. Vale ressaltar que o professor já esteve inserido 
em agências formadoras tanto de graduação como de pós-graduação, o que não foi suficiente para lhe dar condições para a real leitura de diversos gêneros discursivos. Se nos voltarmos para o seu enunciado, de que às vezes é necessário releituras para o favorecimento da compreensão, certamente concordaremos com o professor; algumas leituras, de fato, são de difícil compreensão devido a grande complexidade enunciativa. Contudo, as leituras referidas pelo sujeito, não encontram-se no rol das leituras que poderiam ser consideradas “difíceis”. Mesmo se considerarmos os gêneros secundários, como, por exemplo, a notícia (um gênero bastante citado pelos professores e pelo sujeito P35), veremos que se trata de um texto basicamente informativo e bastante explícito, o que não justificaria problemas de interpretação para pessoas plenamente alfabetizadas, como deveria ser o caso dos professores. Tal fato aponta para além de uma escolarização e formação precárias, uma carente inserção em práticas mediadas pela leitura e escrita.

O sujeito P80, a seu turno, demonstrou dificuldades de interpretação na própria pergunta do questionário, uma vez que não respondeu exatamente ao que foi perguntado, demonstrando que talvez apresente dificuldades de interpretação dos materiais lidos. Nosso estudo aponta para a necessidade de avaliação das competências em leitura e escrita dos professores com o intuito de se repensarem políticas públicas mais adequadas à formação docente considerando suas reais condições de letramento. Ademais, alguns dos professores têm consciência de que apresentam dificuldades de leitura e que estas estão relacionadas ao período da sua escolarização básica e formação em geral; algo que pode ser observado pelo relato que se segue:

Tenho dificuldade na interpretação por não ter sido estimulado no período escolar. (P. 11)

Sobre as políticas para a formação do professor, o ideal seria que os professores fossem ouvidos quanto às suas necessidades e dificuldades para, então, aproximar a formação da realidade vivida por eles no contexto de sala de aula e, assim, buscar um sentido mais amplo para as práticas de linguagem escrita.

Relativamente à aproximação dos cursos de formação das necessidades reais dos professores, Kramer e Souza fazem colocações referentes às diversas possibilidades que eles vêm encontrando em situações de formação:

As diferentes estratégias de formação têm favorecido aos professores falar de suas vidas e ampliar seus conhecimentos, ou eles tão-somente são reduzidos à condição de audiência 
passiva e informações parceladas desvinculadas de seu saber, de sua vida prática, de sua história? (1996, p. 16).

Vale enfatizar a importância de os cursos de formação se aterem às reivindicações que chegam às instituições formadoras, oriundas dos professores, mesmo que elas estejam inicialmente fora das expectativas dos formadores. Entretanto, parece-nos que os cursos de formação, por vezes, têm intenção única de intervir nas práticas pedagógicas, desconsiderando o fato de que a vida na escola é um processo complexo. Para transformar a prática pedagógica, é preciso descrevê-la, e, para descrevê-la, é necessário, antes de qualquer providência, conhecê-la, compreendê-la em sua complexidade (GUEDES-PINTO, GOMES e SILVA, 2005).

Ainda nessa linha de crítica à formação, Justina (2004) assevera que os cursos de formação de professores continuam com as mesmas propostas educacionais do passado, que visam somente à transmissão e não à construção de saberes. Também criticando os programas de formação, citamos Cagliari (1998), que faz a seguinte afirmação:

[...], guiadas por estranhas idéias oriundas das faculdades de educação, não conseguem dar a formação necessária para os professores, os órgãos públicos encarregados da educação passaram a dar periodicamente "pacotes prontos", de acordo com o modismo da época (1998, p. 33).

Concordamos com Cagliari quando diz que se os cursos de formação oferecessem uma formação mais sólida, os professores seriam mais bem preparados e conscientes de suas práticas pedagógicas. Os professores inclusive teriam mais força para recusar "pacotes prontos” que não se justificariam, pois assumiriam a sala de aula com autonomia teóricometodológica.

Kramer e Souza (1996), no tocante a esse assunto, defendem a importância de uma formação na qual seja possível gerar, implementar e consolidar uma política de uso da linguagem escrita, ou seja, desvinculá-la de práticas que não proporcionem o seu uso efetivo em contextos diversos. Para que essa prática ocorra de forma adequada, seriam imprescindíveis na formação dos professores vivências significativas com múltiplos gêneros do discurso, em que a exigência de leitura e de escrita mais aprimorada fosse necessária.

Ainda sobre formação de professor, Berberian e Calheta (2007) fazem alguns questionamentos: 
Se por um lado há o reconhecimento dos programas propostos pelo governo como iniciativas favoráveis à qualificação da prática pedagógica, por outro, pode-se apreender nas experiências práticas, bem como a partir da sistematização teórica de outros profissionais envolvidos com a formação continuada, uma série de contradições e desafios a serem enfrentados, os quais se anunciam nos seguintes questionamentos: Será que o professor efetivamente apropria-se dos conteúdos e conceitos veiculados nos documentos oficiais e em produções acadêmicas que supostamente o tomam como interlocutor? Será que esses programas permitem uma reconstrução das práticas de letramento do próprio professor, a fim de que ele possa assumir seu papel na construção de conhecimentos por parte de seus alunos?

Souza (2008) considera a necessidade de o professor ser parte integrante de seu próprio processo de formação para que as práticas formativas sejam efetivas. Enfatiza que

\begin{abstract}
os professores necessitam ser ouvidos quanto às suas necessidades e dificuldades que permeiam a prática da leitura e da escrita, buscando sentidos para a linguagem escrita de modo a tirar de foco o uso dessa modalidade de linguagem meramente para cumprir metas de planejamento escolar, descontextualizados da vida do aluno e também do professor (P. 51).
\end{abstract}

Acreditamos, seguindo os autores acima, que uma das alternativas para resolver o problema da formação do professor seja por meio da escuta dos professores. A esse respeito, Guedes-Pinto (2006) menciona estudos que vêm elegendo o trabalho com o gênero memórias de leitura, por meio do qual são criados espaços de vivências para que os professores narrem suas trajetórias leitoras, o que possibilita penetrar em enredos bastante singulares e que revelam facetas preciosas a respeito da diversidade existente nas práticas de letramento. A autora acredita que as narrativas auxiliam os professores formadores na compreensão dos percursos de letramento constituídos ao longo de cada história singular. Os depoimentos que são levantados trazem informações relevantes sobre quem são os professores leitores e escritores e sobre como as práticas de leitura e escrita têm se constituído em seus percursos de vida. Dessa forma, os formadores podem aproximar-se dos profissionais do ensino e, nesse encontro, considerar a possibilidade de uma formação mais inclusiva e efetiva do professorleitor.

\title{
Considerações finais
}

Ao refletirmos sobre as práticas de leitura e condições de letramento dos professores chegamos à conclusão de que restritas práticas de leitura convergem igualmente em condições 
restritas de letramento, e que os resultados desse processo podem ser sentidos nos indicadores nacionais e internacionais das condições de alfabetismo dos brasileiros.

Sabemos que as crianças têm duas principais formas de estabelecer uma relação efetiva e afetiva com a leitura, a saber, o meio familiar e o contexto escolar. No caso brasileiro, são poucas as crianças que encontram na família formas intensas de contato com a leitura e inserção ampla em eventos de letramento significativos. Cabe ao professor, desse modo, o papel de despertar o interesse dos alunos, inserindo-os em contextos significativos de uso da língua. Mas como fazer isso? Como aproximar o aluno da linguagem escrita se o professor, ele mesmo, está distante dela? Como tornar o aluno um leitor de fato se o próprio professor não o é? ${ }^{2}$ Como é possível modificar essa situação se as condições do professor indicam sua trajetória histórica de poucas inserções em práticas mediadas pela leitura e escrita?

Acreditamos ser urgente a (res)significação da relação dos professores com a leitura e esta tem de ser iniciada logo no início de sua formação acadêmica. Aos alunos de Letras e Pedagogia devem ser dadas oportunidades de inserção em práticas efetivas de uso da leitura e da escrita; para, a partir dessa intensa inserção, pensar-se em estratégias adicionais para a ampliação das condições letradas dos futuros docentes. Não é possível que se curse uma universidade e se saia dela com dificuldades de interpretação de textos ou com aversão à leitura e à escrita. Aos alunos universitários devem ser criadas condições para que experimentem situações mediadas por gêneros discursivos diversos, para que, por meio dessa vivência letrada, o professor possa da língua escrita se apropriar, de fato.

Seguindo nessa direção, para os cursos de formação continuada, como sugerem vários autores (alguns citados neste trabalho), é necessário partir da escuta do professor, considerando suas reais condições sociais, históricas e culturais. Para conhecê-lo, é necessário dar voz a ele, para, por meio desse discurso, traçar estratégias para poder atingi-lo realmente, o que inclui dar novos sentidos à relação do professor já formado com a leitura.

O que ocorre na atualidade, algo visível no contexto da sala de aula, são professores tentando reproduzir teorias com as quais não têm a mínima intimidade. Mesmo com relação aos documentos oficiais de Língua Portuguesa, como os PCNs, pesquisas (BARBOSA, 2008) apontam para uma ilegibilidade desses documentos por parte dos professores. Apenas para ilustrar, Barbosa afirma que os educadores vêm tomando a proposta de trabalho na perspectiva dos gêneros do discurso de forma semelhante ao trabalho realizado com as tipologias textuais, seja em virtude de correlacionar essa nova teoria com o conhecimento que 
já possuem acerca dos tipos de textos, acreditando ser a mesma proposta, seja porque não sabem exatamente o que propor no lugar das práticas já consagradas, ou por uma falta de compreensão da perspectiva teórica mais atual. Ou seja, não é possível que haja uma transposição direta dos conceitos presentes nesses documentos sem dar condições para que o professor possa se apropriar deles.

Como, para questionar, um professor pode trabalhar com o gênero crônica em sala de aula se ele mesmo não teve a vivência necessária ao domínio desse gênero? Natural, então, que o professor se entregue ao livro didático e fique preso à precária execução dos conhecimentos ali apresentados. Geraldi (2010) acredita que a mentalidade de "executor do livro didático” instaura na identidade do professor o signo da desatualização, uma vez que ele não participa da produção dos conhecimentos veiculados pelo material didático; “ele está sempre atrás destes saberes”, pois são produzidos por outros.

Seria necessário que através do conhecimento da realidade do professor, o que inclui analisar suas condições de letramento, com o qual esta pesquisa contribui, partir para a inserção do docente em amplas, intensas e diversificadas práticas sociais de leitura e escrita. Só assim, ampliando-se o acesso e o domínio do professor aos mais variados gêneros discursivos, é que será possível fazer com que participe da construção dos saberes necessários a uma prática pedagógica eficiente.

\section{Referênciais}

BARBOSA, J. P. Do professor suposto pelos PCNs ao professor real de língua portuguesa: são os PCNs praticáveis? In: ROJO, R. A prática de linguagem em sala de aula: praticando os PCNs. São Paulo: Mercado de Letras, 2008. p. 149-181.

BERBERIAN, A. P.; CALHETA, P. Fonoaudiologia e Educação: sobre práticas voltadas para a formação de professores. In: LOPES FILHO, O. Tratado de Fonoudiologia. São Paulo: Roca, 2007. p. 682-691.

COOK-GUMPERZ, J. Literacy and schooling: na unchanging equation? In: COOKGUMPERZ, J. (Ed.). The Social Construction of Literacy. Cambridge. In: SOARES, M. Letramento: Um Tema Em Três Gêneros. Autêntica. 2003.

GERALDI. J. W. Portos de passagem. São Paulo: M. Fontes, 1997.

. A aula como acontecimento. In: A aula como acontecimento. São Carlos: Pedro e João Editores, 2010, p. 81-101.

JUSTINA, E.W.N.D. Nível de letramento do professor: implicações para o trabalho com 
gêneros textuais na sala de aula. Revista Linguagem em (Dis)curso, v. 4, n 2, jan/jun.2004.

KRAMER, S.; SOUZA, S. J. (Org.). História de professores: leitura, escrita e pesquisa em educação. São Paulo: Ática, 1996.

LAHIRE, B. Sucesso escolar nos meios populares: as razões do improvável. São Paulo: Ática, 2008.

GUEDES-PINTO, A. L.; GOMES, G. G.; SILVA, L. C.B. Percursos de letramento dos professores: narrativas em foco. In: KLEIMAN, A.B.; MATENCIO, M.D.L.M. (orgs) Letramento e formação do professor: práticas discursivas, representações e construção do saber. Campinas: Mercado de Letras, 2005. p. 65-92.

GUEDES-PINTO, A.L. Percursos de letramento em narrativas de professores: subsídios para a reflexão sobre a formação inicial. Horizontes, v. 24, n. 2, p. 151-159, jul./dez., 2006.

SIGNOR, R. Os gêneros do discurso como referenciais para a atuação fonoaudiológica: um estudo de caso. Dissertação (Mestrado em Linguística) - Universidade Federal de Santa Catarina, Florianópolis, 2010.

SOARES, M. Letramento e escolarização. In: RIBEIRO, V. M. (org) Letramento no Brasil.. São Paulo: Global Ação Educativa. Instituto Paulo Montenegro, 2003.

SOUZA, C. H. F. A. D. Análise do conhecimento que os professores têm acerca da conceituação de letramento. Dissertação (Mestrado emDistúrbios da Comunicação Humana) - Universidade Tuiuti do Paraná, Curitiba, 2008.

\footnotetext{
${ }^{1}$ A pesquisa foi orientada pela professora Dra. Ana Paula Berberian.

${ }^{2}$ Conforme Berberian e Calheta não se questiona se o professor é leitor. É sabido que o professor é leitor, o que se questiona é se a qualidade do que lê - e frequência com que lê - são suficientes para garantir uma educação de qualidade para os seus alunos.
} 